\title{
LA CASA GIBBS Y EL MONOPOLIO SALITRERO PERUANO: 1876-1878
}

El objeto de este breve trabajo es mostrar la disposición de Anthony Gibbs \& Sons, y de sus filiales, a apoyar el proyecto monopólico salitrero del Perú con recursos monetarios y los manejos de sus directores en la única empresa que, dada su capacidad de elaboración, podía hacerlo fracasar: la Compañía de Salitres y Ferrocarril de Antofagasta, de la que Gibbs era el segundo mayor accionista. Para el gobierno chileno la causa primaria de la guerra de 1879 fue el intento del Perú por monopolizar la producción salitrera. Bolivia, su aliada secreta desde 1873, colaboró arrendándole y vendiéndole sus depósitos de nitrato, e imponiendo a la exportación del salitre un tributo que infringió la condición -estipulada en un Tratado de Límites- bajo la cual Chile le cedió territorio. Su recuperación manu militari inició el conflicto. A partir de la segunda mitad del siglo pasado esta tesis economicista-legalista fue cuestionada en Chile y en el exterior, desplazando el acento causal al reordenamiento de los mercados de materias primas -de las que los beligerantes eran exportadores- a consecuencia de la crisis mundial de la década de 1870 .

Palabras clave: Guerra del Pacífico, causas, monopolio salitrero, Casa Gibbs.

This brief study aims at showing Anthony Gibbs \& Sons disposition in supporting the Peruvian monopolistic nitrate project with monetary resources and its Director's influences in the only company which, due its production's capacity, could make the project fail: the Chilean Antofagasta Nitrate and Railway Co. in which Gibbs was the second most important stockholder.

According to Chilean government the primary cause of 1879's war was Peru's attempt to monopolize nitrate production. Bolivia, its secret allied since 1873, helped renting and selling him her nitrate fields and imposing a tax on the nitrate exports of the Chilean company in Antofagasta, thus violating the condition stated in a Border Treaty by which Chile had ceded territory. Its recovery through the use of military force was the first act of the conflict.

This economic-legalist thesis was questioned in Chile and elsewhere around the second half of last century, placing war's causes accent on the rearrangement of raw material markets -the warring countries exported them- as a consequence of 1870 decade's world crisis.

Key words: War of the Pacific, causes, nitrate monopoly, the House of Gibbs.

Fecha de recepción: mayo 2007

Fecha de aceptación: diciembre 2007

* Licenciado en Ciencias Jurídicas Políticas y Sociales por la Universidad Católica de Chile. Correo electrónico: mravestm@terra.cl 
Orientados por los trabajos de John Mayo ${ }^{1}$, Roberto Querejazu ${ }^{2}$ y Thomas F. O'Brien ${ }^{3}$ investigamos, durante breves semanas del invierno londinense de 1981, los archivos de la Casa Gibbs -depositados en la Guildhall Library-, hurgando en la correspondencia atingente a la Compañía de Salitres y Ferrocarril de Antofagasta. Sin embargo de no haber logrado examinar los cientos de manuscritos puestos a nuestra disposición con gentileza inigualable, la rebusca nos permitió publicar La compañía salitrera y la ocupación de Antofagasta 1878-18794. Regresamos convencidos de que una segunda revisión de los manuscritos Gibbs (en adelante GMS) podría confirmar la hipótesis que sugerían y que la premura y el farragoso contenido de las carpetas impidieron trabajar: la colaboración prestada por la Casa Gibbs al proyecto peruano de controlar la industria salitrera debió haber ido más allá de sus empeños por limitar la producción de la compañía antofagastina, apreciables en la documentación examinada. La intuición se hizo más patente al ordenar las notas; pero, con cautela, nos limitamos en el libro a advertir la importancia de no perder de vista los intereses privados ligados al proyecto monopólico del Perú ${ }^{5}$. Esas lejanas inquietudes habrían permanecido inertes a no haber mediado una coincidencia.

Hallamos, en una monografía de Ronald Crozier, el missing link no encontrado entre los GMS: un manuscrito que vincula financieramente a la Casa Gibbs -"the House" la denominaban sus miembros- con el arrendamiento, por parte del Perú, de las salitreras del Departamento Litoral boliviano. Y días más tarde vimos el programa en torno de la guerra del Pacífico difundido (mayo 2007) por el canal de televisión estatal chileno, en el que historiadores de los tres países beligerantes fueron consultados por las causas del conflicto. Matices más, matices menos, los entrevistados coincidieron en apuntar al salitre como detonante.

Las escuetas imputaciones de los historiógrafos bolivianos y peruanos reiteraron lo afirmado hace más de un siglo en sus países; en síntesis, que

"la verdadera causa de la guerra que Chile ha declarado al Perú, se encuentra en su desmedida ambición, en el vehemente deseo de apoderarse del litoral boliviano, que encierra grandes riquezas en guano, salitre y minerales" 6 ,

y que el mal manejo del gobierno altiplánico de las franquicias tributarias otorgadas a las industrias chilenas sitas en su territorio brindó el pretexto para que La Moneda decidiera enseñorearse de las calicheras de Tarapacá y del sector boliviano del desierto de Atacama. Constreñido -lo mismo de sus colegas- por las limitacio-

\footnotetext{
1 Mayo John, "La compañía de salitres de Antofagasta y la guerra del Pacífico", en Historia $\mathrm{N}^{\circ}$ 14, Santiago, 1979, 71-102

2 Querejazu Roberto, Guano, salitre, sangre, La Paz, Editorial Amigos del Libro, 1979.

3 O'Brien F. Thomas, "The Antofagasta Company: A case study of peripheral capitalism", en The Hispanic American Historical Review, N 60, Duke University Press, febrero 1980, 1-31.

4 Ravest Manuel, Santiago, Editorial Andrés Bello, 1983.

5 Ravest, op. cit., 95.

6 Contra manifiesto que el gobierno del Perú dirige a los estados amigos con motivo de la guerra que le ha declarado Chile, Lima, Imprenta del Estado, 1879, 14.
} 
nes de la pantalla chica, el historiógrafo chileno siguió las aguas de la versión fundacional de la causa u origen de la contienda, que el diputado Zorobabel Rodríguez resumió, en sus albores, diciendo

“... el Perú comenzó esta guerra... porque empezó estableciendo el monopolio del salitre e indujo a Bolivia primero a arrendarle sus salitreras y enseguida a desconocer los tratados con Chile a fin de redondear su negocio del monopolio"”.

La primera enunciación oficial del binomio economicista-legalista como causa fue el Manifiesto que el gobierno de Chile dirige a las potencias amigas con motivo del estado de guerra con el gobierno del Perú ${ }^{8}$, firmado el 12.4.1879 por el canciller Alejandro Fierro, seguida, entre muchas otras, por la del ministro José Manuel Balmaceda en la circular enviada a nuestras legaciones en el exterior el día antes de la Navidad de $1881^{9}$. Y es probable que la última de naturaleza oficial haya sido la emitida en el contraalegato de 1924 ante el árbitro en la cuestión del plebiscito de Tacna y Arica

"La causa verdadera [de la guerra] -afirmamos en Washington- fue la determinación del Perú de organizar un monopolio gubernativo sobre la producción del salitre en la costa del Pacífico... el impuesto de diez centavos fue autorizado por Bolivia a instancia del Perú que estaba deseoso de completar su monopolio..."10

infringiendo, deliberadamente, el Tratado de 1874, contrato internacional que le impedía establecer nuevos tributos.

A contar de la segunda mitad de la centuria pasada esta exégesis fue cuestionada por escritores nacionales que, haciendo abstracción de factores jurídicos y del honor y dignidad nacional comprometidos en la infracción del Pacto, creyeron encontrar la etiología del conflicto en la fusión de intereses económicos públicos y privados, línea interpretativa que sobrevive en un libro reciente, por muchas razones meritorio ${ }^{11}$. Frente a la crisis mundial de la década de 1870 , que tan seriamente afectó a los países productores de materias primas, agravada en Chile por su inca-

7 Boletín de Sesiones Ordinarias de la Cámara de Diputados (en adelante BSOD), Sesión $13^{\mathrm{a}}$ de 1.7.1879, 161 .

8 En Diario Oficial de la República de Chile (en adelante DO), de 16.4.1879 y en folleto publicado en Santiago, Imprenta Nacional, 1879. En la Imprenta de La Patria, Valparaíso, el folleto fue editado en francés e inglés.

9 Memoria de Relaciones Exteriores y de Colonización, Santiago, Imprenta Nacional, 1882, 47 y ss.

10 The counter-case of the Republic of Chile, 254 y 305. Sin año ni pie de imprenta.

11 Ortega Luis, Chile en ruta al capitalismo. Cambio, euforia y depresión 1850-1880, Santiago, LOM Ediciones, 2005, especialmente 434 y ss. En Los empresarios, la política y los orígenes de la guerra del Pacífico, Santiago, FLACSO, 1984, Ortega ya había dado a conocer sus -a nuestro entender sesgadas- apreciaciones sobre el papel jugado por los empresarios chilenos. Le precedieron trabajos tales como los de Julio César Jobet, Ensayo crítico del desarrollo económico-social de Chile, 1951, 45 y ss., Marcelo Segall, Desarrollo del capitalismo en Chile. Cinco ensayos dialécticos, 1953, 143 y ss., y Luis Vitale, Interpretación marxista de la historia de Chile, cuyo tomo IV, Ascenso y declinación de la burguesía chilena, fue publicado en Frankfurt en 1976 y en Santiago por LOM Ediciones en 1993. 
pacidad de amoldarse al sistema de producción capitalista, la oligarquía exportadora habría puesto sus ojos en el nitrato boliviano y peruano como substituto del cobre y el trigo en los mercados internacionales ${ }^{12}$. A la pregunta de si "se hace la guerra por la patri o por el salitri”, que según el general chileno José Velásquez formulaban los bolivianos -con su particular pronunciación- en Antofagasta ${ }^{13}$, aquellos escritores postularon, derechamente, que por el salitri.

Al revisionismo contribuyeron investigadores estadounidenses y europeos ${ }^{14}$, entre ellos William F. Sater que desde 1973 viene añadiendo una nueva hipótesis a las múltiples intentadas para explicar los móviles de la guerra: la precaria estabilidad política del gobierno del Presidente Pinto, insinuada en 1879 por el canciller limeño Manuel Irigoyen ${ }^{15}$. La Moneda vendría a tierra si, lo mismo que meses antes hiciera frente a la Argentina por la cuestión de la Patagonia, retrocedía ante la infracción boliviana de un Pacto internacional. La guerra habría sido una tabla de salvación política a la vez que económica, dados los quebrantos experimentados en ambos aspectos por el país ${ }^{16}$.

La coincidencia del hallazgo de Crozier con el recordado programa de televisión nos sugirió el propósito de sistematizar los antecedentes recogidos en Londres acerca de la ayuda brindada por Anthony Gibbs \& Sons, y sus filiales en Lima y Valparaíso, al legítimo proyecto monopólico salitrero del Perú. No para afianzar una de entre el caleidoscopio de hipótesis explicativas, sino por tratarse de un hecho poco investigado en torno de los móviles atribuidos al enfrentamiento, mate-

12 Según esta tesis el cambio de esquema implicaba alteraciones de orden social, económico y político que la oligarquía no estuvo dispuesta a realizar, pasividad que, en definitiva, habría hecho de Chile, un caso de desarrollo frustrado. Ese es el título del libro con que en 1950 Aníbal Pinto

-adherente, en su momento, a la corriente nacionalista chilena de comienzos del XX-planteó que el punto de inflexión del desarrollo del país tuvo lugar cuando "la decadencia" o "desaparición" del "ánimo pionero" del empresariado permitió al capital extranjero, mayoritariamente inglés, controlar la industria del salitre. La "desnacionalización” salitrera halló su mayor exponente en Ramírez Necochea, La guerra civil de 1891: antecedentes económicos, 1951, y Balmaceda y la contrarrevolución de 1891, $3^{\mathrm{a}}$ edición, 1972, en la que se hizo cargo de los cuestionamientos a su obra planteados en la tesis doctoral de Harold Blakemore, The chilean revolution of 1891, para entonces inédita, y "The chilean revolution of 1891 and its historiography", aparecida en The Hispanic American Historical Review, de agosto de 1965.

Una visión distinta acerca de los negativos efectos de la que O'Brien llamó "symbiotic relationship" entre formas de producción capitalista y precapitalista en Chile. The nitrate industry and Chiles's crucial transition: 1870-1891, 145, en Cariola y Sunkel Un siglo de historia económica de Chile 1830-1930, Santiago, 1990 y en Mamalakis, The growth and structure of the chilean economy. From independence to Allende. New Haven, 1976. En el capítulo V del vol. I. del Tomo I de su Historia de Chile, Gonzalo Vial realiza un lúcido análisis del tema.

13 Carta de 12.4.1879 en Revista Chilena de Historia y Geografía (en adelante $R C H G$ ), $\mathrm{N}^{\circ} 29$ de $1918,367$.

14 Pueden mencionarse, entre muchas, las investigaciones de Bader. A willingness to war: a portrait of the Republic of Chile during the days preceding the war of the Pacific; Burr; By reason or force, Chile and the balancing of power in South America, 1830-1905; Cluny, Atacama; Millington; American Diplomacy and the war of the Pacific; Farcau; The ten cents war.

15 Contramanifiesto que el gobierno del Perú dirige..., 1.

16 La aproximación de Sater se inició en The heroic image in Chile. Arturo Prat, Secular Saint, University of California Press, 1973, 22 y ss., cobró más fuerza en Chile and the war of the Pacific, University of Nebraska Press, 1986, 15 y 16, manteniéndose en el reciente Andean Tragedy. Fighting the war of the Pacific, 1879-1884, University of Nebraska Press, 2007, 39 y ss. 
ria que creemos -a diferencia de Sater ${ }^{17}$ - continúa siendo la más relevante en el estudio de la guerra del Pacífico.

\section{“LA CASA” Y SUS RELACIONES CON LA INDUSTRIA SALITRERA EN 1876}

Siendo las actuaciones de "la Casa" en pro del monopolio salitrero el tema preciso y conciso de las páginas siguientes, es necesario reconstituir el contexto de la industria del nitrato en 1876, y las ligazones que con ella mantenía Gibbs en Perú y Bolivia. La ley de 1875 que autorizó al gobierno peruano a comprar todas las oficinas salitreras de Tarapacá no obligaba a enajenarlas pero fijaba a la exportación del fertilizante derechos aduaneros tales que, en la práctica, forzaba a hacerlo. Casi todas las "paradas" (utilizaban fuego directo para lixiviar el caliche) fueron adquiridas de inmediato, prosiguiendo las negociaciones con los dueños de las "oficinas" (con maquinaria a vapor) que sortearon la crisis provocada por la caída del precio del nitrato y los lesivos efectos del frustrado intento (1873) de estancar su venta en manos del Estado. La Tarapacá Nitrate Company, controlada por la filial peruana de "la Casa" y propietaria de las oficinas Carolina y Limeña, había perdido 484.524 soles entre 1873 y 1875 , en circunstancias que la inversión llegaba en ese último año a 1.274 .524 soles $^{18}$. De manera que la posibilidad de abandonar un negocio en declinación vendiendo las oficinas al Estado y celebrando con su representante -el consorcio de los Bancos Asociados- contratos de elaboración para operarlas era, de suyo, atractiva. Más todavía si su precio estimado en 1.250.000 soles era aceptado, como en definitiva lo fue tras una negociación que, además, significó a William Gibbs \& Co. (WGC) suscribir contratos de elaboración por 500.000 quintales anuales ${ }^{19}$ pagaderos al razonable precio de 1,70 sol por quintal español de 46 kilos ${ }^{20}$. "Paradas" y "oficinas" fueron pagadas con certificados, suerte de pagarés o bonos que el gobierno se comprometió a rescatar -a un tipo de cambio prefijado- dentro de dos años, durante los que ganarían el $8 \%$ de interés anual. En el caso de las oficinas de Gibbs el cierre de negocio fue considerado tan exitoso por la matriz londinense que escribió a su filial felicitándola y manifestándose dispuesta a apoyar el éxito de la nacionalización ${ }^{21}$, a la que colaboraba financieramente desde el mes de mayo según se verá.

A través de Guillermo Gibbs y Cía. (GGC) "la Casa" era accionista de la Compañía de Salitres y Ferrocarril de Antofagasta (CSFA), sociedad anónima constituida en Valparaíso y controlada por Agustín Edwards Ossandón, el acau-

17 Sater, Andean Tragedy, 40.

18 O'Brien Thomas F., The nitrate industry and Chiles's crucial transition: 1870-1891, New York University Press, 1982, 31.

19 Cruchaga Miguel, Salitre y Guano, Madrid, Editorial Reus, 1929, 300.

20 Billinghurst Guillermo, Los capitales salitreros de Tarapacá, Santiago, Imprenta de El Progreso, 1889, 41; O'Brien, The nitrate industry and Chiles's..., 32.

21 GMS $11.471 / 8$ de 15.9 .1876$. 
dalado banquero chileno. En 1876 la CSFA era dueña de la única oficina en territorio boliviano; su nuevo establecimiento elaborador, construido en el mismo puerto de Antofagasta, estaba próximo a entrar en producción, y el ferrocarril de su propiedad, que bajaría caliches de buena ley desde los depósitos recién descubiertos a 150 kilómetros del puerto, acababa de ser autorizado para portear, cobrando por el servicio, los minerales argentíferos de Caracoles y los cupríferos del interior del desierto de Atacama. Hasta entonces el negocio no había sido exitoso del todo, pero se abrían buenas perspectivas a pesar de la no siempre cómoda relación societaria entre Edwards y sus socios ingleses. Los roces derivaban, principalmente, de la resistencia de don Agustín a nombrar a GGC agente para la venta en Europa. Tras un aumento de capital no suscrito por Gibbs don Agustín pasó a controlar el $42 \%$ del capital accionario versus el $25 \%$ de "la Casa", la que evaluaba su inversión en Bolivia en $£ 141.804$, monto bastante inferior a las $£ 228.757$ en que estimaba los activos transferidos al gobierno del Perú $^{22}$.

\section{COINCIDENCIA ENTRE LOS INTERESES DE GIBBS Y LOS DEL ESTADO PERUANO}

Con arreglo a la citada ley de 1875 el Presidente Manuel Pardo encargó al consorcio integrado por cuatro bancos - Bancos Asociados de Lima- gestionar y administrar la nacionalización de la industria salitrera, facultándole para realizar las operaciones destinadas a transformar al Estado en el único productor y comercializador del fertilizante. "La Casa" obtuvo del consorcio bancario, en mayo de 1876, la exclusividad de la consignación del nitrato proveniente de la elaboración que él contrataba con los ex dueños de las oficinas, y el consorcio recibió de Gibbs un anticipo de $£ 40.000^{23}$.

Los intereses del Estado, de los Bancos Asociados y de "la Casa" confluían armónicamente en dos puntos fundamentales: el volumen de producción y el de exportación del salitre. El consorcio controlaría la primera a través de la cuota acordada con cada elaborador en el respectivo convenio, y los tributos a la exportación de los productores renuentes a vender sus oficinas se encargarían de desalentarla. En los GMS 11.132 existen varias constancias de lo anterior, incluso de acuerdos tripartitos -gobierno, Bancos Asociados y Gibbs- para restringir la exportación durante algunos períodos y mantener elevado el precio. Del tonelaje exportado dependía, en definitiva, la comisión que "la Casa" percibiría por la venta del producto, sin competencia alguna, en el mercado europeo, y también la utilidad de los bancos tras el entero, en arcas fiscales, de determinadas sumas mensuales, de servir la deuda externa e interna y el empréstito -nunca colocadopara el rescate de los certificados o bonos emitidos en pago de las oficinas tarapaqueñas.

22 GMS 11.049/A de 30.4.1875 y de 30.4.1876.

23 GMS 11.132 de 29.4.1876; 11.121 de 30.5.1876. 
La nacionalización buscaba allegar recursos para sacar al país de la bancarrota en que se debatía, agudizada por la crisis mundial y la consecuente dificultad de contratar empréstitos que, garantidos con hipotecas sobre las covaderas, habían permitido al Perú vivir durante décadas y emprender su costosa e inadecuada política ferroviaria, causa principal del crónico déficit presupuestario que el partido civilista, desde agosto de 1872 en el poder, se empeñaba por superar. Con la producción salitrera en sus manos y habiendo renegociado con Dreyfus ${ }^{24}$ su exclusividad para la venta del guano -desde siempre de propiedad del Estado y cuya tendencia a la baja era manifiesta ${ }^{25}$ - el gobierno quedaría en situación de regular la ruinosa competencia que al detritus de guanayes y piqueros hacía el caliche tarapaqueño. No solo eso. Podría controlar los precios de los fertilizantes nitrogenados, procurando paliar los efectos recesivos de la crisis sobre los mercados internacionales de materias primas.

Fuera de los yacimientos de Tarapacá no existían más depósitos salitrales que los ubicados en los sectores boliviano y chileno del desierto de Atacama. Que los últimos llegaran a explotarse era algo tan incierto que no valía la pena preocuparse por el momento ${ }^{26}$. Tampoco de la exportación que hicieran los particulares tarapaqueños. Quedarían fuera del mercado al elevarse los derechos de exportación, que, en julio de 1878, permitieron al Presidente Mariano Ignacio Prado totalizar la nacionalización ${ }^{27}$. El único riesgo para el control del negocio provenía, por tanto, de los yacimientos bolivianos en manos del Estado y de algunos pocos particulares, entre ellos la CSFA. Salvo los explotados por esta el resto permanecía ocioso; pero existía el riesgo de que, puestos en actividad, entregaran al mercado 6 millones de quintales anuales ${ }^{28}$. A evitar esa contingencia se encaminaron los coincidentes intereses de "la Casa", del gobierno limeño y de su representante, el consorcio bancario.

\section{ARRENDAMIENTO DE LOS YACIMIENTOS BOLIVIANOS}

En la época que nos ocupa -1876- además de los depósitos en el Salar del Carmen y Salinas, pertenecientes a la CSFA, había muchos denunciados, muy pocos adjudicados y ninguno trabajado en las vecindades del río Loa, en la pampa del Toco, al interior de Tocopilla. Por Decreto de 13.1.1876 el Gobierno altiplánico convocó a licitación pública para entregar en arrendamiento todas las calicheras no adjudicadas. Dos proponentes presentaron ofertas, triunfando la de Juan Gilber-

24 Bonilla Heraclio, Guano y burguesía en el Perú, Lima, IEP ediciones, 1974, 108.

25 Ibid.

26 Bermúdez Oscar, Historia del salitre desde sus orígenes hasta la guerra del Pacífico, Santiago, Ediciones Universidad de Chile, 1963, 297 y ss.; Greenhill \& Miller, "The Peruvian Government and the nitrate trade, 1873-1879", en Journal of Latin American Studies $N^{\circ}$ 5, 1973, 124.

27 Yépez Ernesto, Perú 1820-1920, cien años de desarrollo capitalista, Lima, Instituto de Estudios Peruanos, 1972, 112.

28 Billinghurst Guillermo, Rápida ojeada sobre la cuestión del salitre, Valparaíso, Imprenta El Mercurio, 1875, 51. 
to Meiggs -empresario yanqui hermano de Enrique, el constructor de líneas férreas en el Perú y Chile- que ofreció arrendarlas por 20 años, pagando el canon de 120.000 bolivianos anuales en cuotas mensuales de 10.000 y quedando en libertad para "ceder el contrato a terceros de cualquier nacionalidad". El oferente y sus eventuales cesionarios podrían

"elevar y exportar la cantidad de caliche y salitre que se halle por conveniente y de los depósitos que le plazca sin que esté obligado a trabajar en otros puntos que los que le convenga, debiendo entenderse que los demás depósitos que adquiera según la contrata, y los no explotados, quedan amparados por el término de este contrato (20 años)"29

gozando de las mismas garantías tributarias que el Tratado de Límites de 1874, celebrado entre Bolivia y Chile, confería a las empresas de sus nacionales radicadas en el Departamento Litoral de la vecina República (exención de derechos de exportación durante 25 años), franquicias que -siempre se olvida- ella extendió a todas las industrias radicadas en aquel Departamento ${ }^{30}$. Por otra de las bases de la oferta el Palacio Quemado quedaba impedido de producir y exportar salitre por sí, o por interpósita persona, durante el lapso del arrendamiento. La base transcrita más esta última blindaban el derecho de Meiggs a mantener ociosas las calicheras arrendadas, sin peligro de perderlas por "caer en despueble". El negocio fue cerrado el 18.3.1876 con la suscripción de la correspondiente escritura pública $^{31}$.

\section{INTERVENCIÓN DE GIBBS EN EL ARRENDAMIENTO DE LAS SALITRERAS BOLIVIANAS}

Antes de convenir con los Bancos Asociados la comercialización del salitre el Palacio Pizarro discutió con Gibbs la opción de entregarle, directamente, la consignación del producto, función que por décadas ejerciera respecto del guano. Los borradores del abortado contrato forman parte del legajo GMS 11.132. Anexado a uno de ellos halló Ronald Crozier el manuscrito, sin firma ni fecha, que trascribió en la monografía publicada por la revista Historia ${ }^{32}$ de la Pontificia Universidad Católica de Chile. Su texto es el siguiente:

"Artículos reservados: Queda estipulado reservadamente, aunque con la misma fuerza legal, que la contrata por escritura pública:

29 El Ferrocarril de 10.7.1880.

30 Tratado de Límites entre Bolivia y Chile 1874-1875, La Paz, Imprenta de la Unión Americana, $1875,67$.

31 Archivo Histórico del Ministerio de Relaciones Exteriores de Chile (en adelante AHMRE), Fondo Perú Vol. 438; Aldunate Carlos, Leyes, decretos y documentos relativos a las salitreras, Santiago, Imprenta Cervantes, 1907, 53-60.

32 Crozier Ronald "El salitre hasta la guerra del Pacífico. Una revisión”, en Historia $\mathrm{N}^{\circ} 30$, Santiago, 1997, 117. 
$1^{\circ}$ Que la subvención de 10.000 bolivianos al mes que el Gobierno del Perú tiene que pagar al de Bolivia por el arrendamiento del Toco, se adelantará al Gobierno de Bolivia por la casa de Gibbs, la que se reembolsará de estos adelantos ["intereses" está escrito al margen] de los primeros productos líquidos del salitre, lo mismo que hace con los gastos naturales del negocio en la costa.

$2^{\circ}$ El Gobierno del Perú se compromete a que todo el salitre que por su cuenta se elabore en Bolivia, sea entregado a la casa Gibbs en los mismos términos que prescribe la contrata por escritura pública para el salitre que por cuenta del Estado se produzca en el Perú (los destacados son nuestros)".

En las microfichas del archivo Gibbs -en posesión de la Biblioteca de Humanidades de la mencionada Universidad- pudimos observar el eslabón perdido no descubierto en nuestra investigación de 1981. El manuscrito es un testimonio indubitable de la disposición de "la Casa" a colaborar financieramente para que el gobierno del Perú tomara en arriendo los yacimientos bolivianos y suprimiera su amenaza. A cambio de que el Estado le consignase "todo el salitre que por su cuenta se elabor[e]en Bolivia”, Gibbs adelantaría los recursos para el pago de las rentas del arrendamiento.

Es importante señalar, aunque sea incidentalmente, que el hallazgo de Crozier juega en favor de la tesis chilena de haber el arrendamiento sido resultado de una triangulación diseñada por Bolivia, Meiggs y Perú, toda vez que el GMS se anticipaba a atribuir al Gobierno peruano la condición de arrendatario, la que adquiriría dos meses más tarde gracias a la cesión hecha por el empresario yanqui. En otras palabras, el manuscrito era premonitorio; redactado durante abril -mientras Gibbs negociaba con el Presidente Pardo la consignación que en definitiva recibió de los bancos en mayo- avizoró la cesión del arriendo que Meiggs propondría en junio y se perfeccionaría en el mes siguiente "por ser de la más alta importancia para los intereses fiscales"33. La sugestiva premonición será materia de un futuro estudio*. En el ínterin queda asentada la huella del auxilio financiero de Gibbs a la concreción del monopolio salitrero.

\section{PREguntas ACUCIANTES}

¿Por qué la reserva del anexo al borrador del frustrado contrato de consignación del salitre? ¿Quién ideó la negociación? ¿Por qué una triangulación?

Respecto de la primera pensamos que Anthony Gibbs \& Sons, antigua y prestigiosa casa de "la City", deseaba mantener en la penumbra su injerencia en una operación que para ella conllevaba un delicado conflicto de intereses, cuestionable, eventualmente, a los ojos de la -no siempre- rígida ortodoxia mercantil británica, y objetable, definitivamente, a los de sus socios en la Compañía de Salitres y

33 AHMRE Fondo Perú, Vol. 438; Aldunate, op. cit., 69.

Nota del S. de R: ver Boletín de la Academia Chilena de la Historia, № 117, 2008. 
Ferrocarril de Antofagasta. No han sido descubiertos, que sepamos, antecedentes de que "la Casa" les impusiera de sus propósitos.

En cuanto a quién ideó la triangulación, el estado de las investigaciones impide dar respuesta. Perú era el gran beneficiario. No cabe descartar a Meiggs como hizo Crozier por estimarle carente de recursos y no pensar en volver al Perú ${ }^{44}$. Tenía fortuna, regresó a Lima a finales de $1879^{35}$ y a Chile en 1882 para asumir la construcción de la vía férrea de Taltal a las salitreras del interior ${ }^{36}$. Construyó ferrocarriles en Argentina y fue contratista del subway londinense ${ }^{37}$. Tampoco corresponde eliminar a Bolivia aunque aparezca como la menos beneficiada por la especulación. El arriendo no era despreciable; representaba casi el 7\% de los ingresos nacionales del Presupuesto Bienal 1878-187938. Con todo, durante su discusión el diputado Franklin Alvarado procuró revocar el "tan fatal" arrendamiento "inventado... para ahogar en su nacimiento la industria salitrera en Bolivia" 39 . La Casa Gibbs también resultaba beneficiada y conocía como nadie el negocio salitrero.

Respecto del por qué de la triangulación, innecesaria por ser un negocio susceptible de llevarse directamente por los gobiernos, se han excogitado diversas hipótesis $^{40}$; nosotros creemos que perseguía evitar posibles reacciones chauvinistas en la clase política boliviana -tensionada por conflictos aduaneros con Perú- y/o su exigencia de una renta de arriendo más elevada que la cobrable a un particular.

\section{TENTATIVAS DE RESTRINGIR LA PRODUCCIÓN DE LA COMPAÑía DE SALITRES Y FERROCARRIL DE ANTOFAGASTA DURANTE 1876 Y 1877}

El riesgo concreto para el proyecto peruano era la producción de la Compañía de Salitres y Ferrocarril de Antofagasta (CSFA), empresa de la que "la Casa" era segundo mayor accionista. Se estimaba en 7.000 toneladas mensuales la capacidad instalada del nuevo plantel en suelo boliviano, en circunstancias que los Bancos Asociados contemplaban poner alrededor de 26.000 toneladas mensuales en el mercado $^{41}$. Varios GMS acreditan los esfuerzos de la matriz londinense y de sus ramas de Valparaíso y Lima para obtener que la compañía chilena constriñera su

34 Crozier, op. cit., 116.

35 AHMRE Fondo Bolivia, Vol. 85; Aldunate, op. cit., 79.

36 Archivo Nacional. Notarial Valparaíso (en adelante $A N N V$ ), Pastene, $2^{\circ}$ semestre 1881 , fs. 1150 .

37 Datos obtenidos a través de google.com.

38 Presupuesto y Ley Financial de la República de Bolivia para los años de 1878 y 1879, La Paz, Imprenta de La Libertad, $1879,1$.

39 Tagle Enrique, El negociado del salitre, Buenos Aires, Imprenta y Encuadernación de El Pueblo Español, 1901, 10-12.

40 V. gr.: Manifiesto que el gobierno de Chile dirige... 12 y ss; Aldunate Carlos, Alegato pronunciado por... ante la Iltma. Corte de Santiago en defensa de D. Enrique Sloman, Santiago, Imprenta Cervantes, 1906, 39; Barros Luis, La cuestión del Pacífico y las nuevas orientaciones de Bolivia, Santiago, Imprenta Universitaria, 1922, 68.

41 Madueño, Ricardo "La industria del salitre en Perú antes de la guerra del Pacífico", en revista El Mercurio Peruano, Lima, 1920, 85; Billinghurst, Los capitales salitreros... 41 
elaboración y restituyera a la filial porteña la exclusividad de la venta del nitrato. A O'Brien se debe el hallazgo de los pertinentes a su afirmación de haber sido el Presidente Pardo, en persona, quien urgió a Gibbs a garantizar "el éxito del proyecto limitando la producción antofagastina para asegurar el aumento del precio del salitre y el resultado financiero necesario para dar término a la expropiación" 42 .

Entre mayo y junio de 1876 -coincidiendo con la asunción de "la Casa" como exclusiva consignataria del salitre- los directores de Gibbs en la CSFA promovieron, sin éxito, la adopción de acuerdos de directorio a fin de limitar la elaboración; también fracasaron los intentos realizados durante $1877^{43}$. La irreductibilidad de Agustín Edwards les hizo escribir a Londres que procurar alinearlo con las políticas de "la Casa" era igual que "tratar de casar dos personas a la fuerza"44. La tozudez de don Agustín debía corresponder a que no estaba dispuesto a restringir las posibilidades de comercializar el nitrato en momentos en que el volumen de venta y el precio del cobre, mineral del que era el mayor exportador, seguían bajando en los mercados externos ${ }^{45}$.

\section{ÚlTIMO INTENTO DE LIMITAR LA PRODUCCIÓN DE LA CSFA: ACUERDO DE 1878 ENTRE la Peruvian Guano Co. y Anthony Gibbs \& Sons. El fantasma DE LOS 10 CENTAVOS}

A comienzos de 1878 los hombres de Gibbs en la CSFA reforzaron sus intentos debido a que "la Casa" estaba entonces empeñada en asumir la gestión dejada por el consorcio bancario, la que, además, le permitiría recobrar la exclusividad de la comercialización del nitrato de sodio. El Presidente Mariano Ignacio Prado había desahuciado el convenio con los Bancos Asociados y "la Casa" perdido su condición de agente de ventas.

Mas no era Anthony Gibbs \& Sons la única aspirante a adjudicarse el contrato fiscal que permitiría manejar el universo de la industria salitrera: la Peruvian Guano Co. Limited, integrada por inversionistas europeos y peruanos, también pugnaba por lograrlo -a la par que competía con Dreyfus en la venta del guano en Europa y Norteamérica ${ }^{46}$. Los rivales llegaron a un acuerdo confidencial cuyas bases están entre los GMS 11.471/5. "La Casa" retiraba su postulación dejando a su ex antagonista el camino libre a trueque de ciertas condiciones, la principal de las cuales era ser la única consignataria del nitrato.

Hemos llegado a un acuerdo con el grupo de J. T. Canevaro (Peruvian Guano Co.). Convinimos provisoriamente suspender acciones tendientes a obtener del Gobierno Peruano la consignación del nitrato de soda, recibiéndola permanentemente de ellos,

42 O’ Brien, “The Antofagasta company: a case study of peripheral capitalism”... 13.

43 GMS 11.470/1.

44 GMS 11.121 de 30.5.1876 y 21.6.1876; GMS 11.120 de 14.06 .1876 y GMS $11.470 / 1$ de 13.07.1877.

45 GMS $11.470 / 2$ de 16.3 .1877

46 Bonilla, op. cit., 108. 
comunicó “privada y confidencialmente" (private and confidential) a Valparaíso Henry Gibbs, el "jefe de la Casa", por carta de 16.4.1878. Informó a la rama chilena que en reunión celebrada con el representante de la Peruvian Guano (De Laski), había aquel demostrado

“gran preocupación por la posición que, como competidora, podría tener la Compañía de Antofagasta. Inclusive intentó colocar como condición que nosotros (Gibbs), de alguna manera y a cualquier precio, asumiéramos el control de la Compañía para los efectos de limitar su producción a una determinada cantidad".

Henry Gibbs le había explicado que la participación accionaria de su Casa en la empresa chilena $(25 \%)$ no le permitía imponer decisiones, pero que pensaba en que "sería una sabia medida de parte de la Compañía de Antofagasta allanarse a algún arreglo". Y prosiguiendo con la información a sus subordinados razonó diciéndoles que el negocio a emprenderse en Perú

“permitirá a la Compañía de Antofagasta obtener condiciones muy favorables a cambio de su cooperación. Por otra parte, la Compañía no debería olvidar que si estira demasiado la cuerda terminará indefectiblemente por cortarla. Y esto sucederá si incrementa su producción a un extremo en que haga imposible, para quienes lleguen a manejar el negocio del salitre peruano, mantener los precios en un nivel tan satisfactorio como el actual".

Pero el más poderoso argumento que veladamente les sugirió esgrimir para doblegar a la mayoría en el directorio de la CSFA fue

"la hostilidad que la Compañía se acarrearía de parte del Gobierno peruano, susceptible de traducirse en intrigas interminables entre ese Gobierno y el de Bolivia, a menos de allanarse a algún acuerdo.

Sabemos ya que el Congreso boliviano ha autorizado al Ejecutivo a imponer un impuesto de 10 centavos por quintal al nitrato de Antofagasta, y pensamos en que el peligro de que los privilegios de la Compañía sean violados con mayor intensidad aumentará en la proporción en que aumente el interés de un gobierno vecino porque deban serlo (as it is made more and more to the interest of a neighbouring Government that they should be so)".

Estos párrafos hacen ocioso todo comentario; mas no lo es rememorar lo que doce años más tarde dijo su autor al Foreign Office, molesto por el apoyo brindado en Chile a John Thomas North, "el Rey del Salitre": "Espero que el Foreign Office no olvidará que mi Casa sabe realmente todo lo que puede saberse acerca de la costa occidental de S. América"47. ¿Qué sabía "el jefe de la Casa" en 1878 sobre el origen del tributo? Debe suponérsele mejor informado que Thomas Comber, presidente de la CSFA tras el fallecimiento de Edwards, y que George Hicks, el admi-

47 Blakemore Harold, Gobierno chileno y salitre inglés 1886-1896: Balmaceda y North, Santiago, Editorial Andrés Bello, 1977, 151. 
nistrador de la oficina de Antofagasta, quienes presumían ser el resultado de intrigas del gobierno peruano ${ }^{48}$.

En el párrafo siguiente Henry Gibbs continuó señalando

“...que siendo importante para la Compañía de Antofagasta llegar a un acuerdo equitativo para los tenedores (de bonos o"bonholders") del salitre peruano, dijimos al señor De Laski que sin embargo de que no podíamos pretender controlar las decisiones de la Compañía, él y sus amigos (la Peruvian) deberían asumir y confiar en que ejerceríamos nuestros mejores oficios, y toda la influencia que pudiéramos, en orden a procurar, si fuese posible, lograr un acuerdo satisfactorio para ellos".

De Laski no quedó satisfecho -prosiguió "el Jefe"- con la buena disposición mostrada por "la Casa"; era "tanta la importancia" que para la Peruvian Guano significaba saber si la CSFA limitaría o no su producción a 5.000 toneladas mensuales que esperarían una respuesta concreta "antes" de abocarse al negocio (before comitting themselves to the business). Y al marcharse había rogado telegrafiar de inmediato a la filial chilena, dejando en manos de su interlocutor el borrador de "Bases de Acuerdo" a suscribirse entre Anthony Gibbs \& Sons y la Peruvian Guano Company. Una hacía responsable a "la Casa" de la restricción.

Ese fue el contenido de la carta del 16.4.1876 escrita por Henry Gibbs para explicar el telegrama urgente que seis días antes había dirigido a Guillermo Gibbs y Cía., telegrama que debió venir en clave atendida la confidencialidad de su texto

"Estamos en negociaciones por todo el nitrato de sodio a nuestra consignación Europa. Tal monopolio nuestras manos muy importante para Compañía Antofagasta, pero negociación en peligro de quiebre si Compañía Antofagasta no accede limitar producción a 5.000 toneladas mensuales. Estamos de acuerdo condiciones que consideran interés accionistas. (Siguen palabras ilegibles aparentemente relativas a los Directores de Edwards en la CSFA). Respondan de inmediato por telégrafo su decisión o condiciones. Lo siguiente es privado y confidencial: Hemos llegado a acuerdo con el grupo de Canevaro. Convinimos provisoriamente suspender acciones relativas competencia consignación del salitre del Gobierno, recibiéndola permanentemente de ellos" $"$.

Tan pronto llegó el telegrama fue consultada la opinión de gran parte de los accionistas, que rechazó -comunicó GGC a Londres-

"toda posibilidad de restringir la producción a 5.000 toneladas mensuales, sin perjuicio de que cerrado el negocio por la Peruvian Guano Co. y todo el salitre consignado a nuestra Casa en Europa podrían estar en condiciones de comprometerse a esa limitación" 50 .

\footnotetext{
48 GMS 11.120 de 20.5.1878 y GMS 11.128 de 11.3.1878.

49 GMS $11.471 / 5$ de 16.4 .1878 .

50 GMS 11.128 de 15.4.1878 y GMS $11.470 / 2$ de 16.4.78.
} 
La mayoría del directorio acordó, en consecuencia, negarse a la solicitud, dejando constancia de su disposición a fijar en 5.000 toneladas el máximo de la producción mensual. Henry Gibbs no desesperó. Entregó a De Laski un contraproyecto de la base que responsabilizaba a su Casa de la producción antofagastina. En reemplazo se obligaba a

"hacer sus mayores esfuerzos para procurar, durante la vigencia de nuestro acuerdo con la Peruvian Guano Co., que la exportación de salitre por la Compañía de Antofagasta no exceda, en ningún año, de un quinto de la cantidad consumida mundialmente en el año anterior, y a empeñarse en inducirla a limitar su producción a 5.000 toneladas mensuales durante los primeros doce meses del citado acuerdo" 51 .

Aceptada que fue por la Peruvian Guano Co., el directorio de la CSFA debió pronunciarse en mayo sobre la solicitud de reconsideración del acuerdo anterior, pedida por GGC en función de la base transcrita. En nota separada "el jefe" le escribió estas frases demostrativas de su pragmatismo

"Pensamos en que lo anterior (la base entregada a De Laski) es todo cuanto podemos hacer teniendo en consideración nuestro relativo interés en la Compañía de Antofagasta. En otras palabras, si así lo dispusiéramos, mañana podríamos vender nuestras acciones y lavarnos las manos de toda obligación bajo esta cláusula (we might, if so disposed, sell our shares tomorrow and wash our hands of all obligations under this clause)"52.

El directorio reiteró su negativa, incluyendo la de entregar a Gibbs la consignación del nitrato antofagastino ${ }^{53}$. En la sesión de junio el director Brice Miller volvió a la carga aduciendo que para el negocio en Perú la "limitación era esencial" porque debían adelantarse grandes sumas de dinero al gobierno. Expresó que no se trataba solamente de un negocio de Gibbs sino de varias firmas inglesas, añadiendo que

"si bien para Anthony Gibbs \& Sons era suficiente garantía la disposición demostrada por el Directorio de la Compañía de Antofagasta, los asociados de aquella exigen que esa buena disposición conste de un acto oficial. Propuso, por tanto, aclarar los acuerdos de 15 de abril y 13 de mayo".

Por unanimidad el directorio adoptó este acuerdo, cuya redacción propuso Miguel Saldías.

"Que el límite de producción en 7.000 toneladas (mensuales) fijado por los acuerdos de 15 de abril y 13 de mayo para asociarse al monopolio no se entiende de una manera definitiva sino que podría reducirse esa limitación a 5.000 toneladas mensuales cuando se haya de fijar las demás condiciones del arreglo y se conozcan las bases según las cuales se establece el monopolio; y aun cuando no se puede contraer por ahora (una) obligación determinada, se halla, sin embargo (el directorio), en el caso de manifestar 
que la Compañía propenderá al establecimiento del monopolio limitando su producción en proporción equitativa" 54 .

"La Casa" felicitó a su filial porteña por haber logrado convencer al resto de los directores de la CSFA que "no pueden comerse su pastel y conservarlo"55. En realidad, ni siquiera lo habían mordido: estaban conscientes de que el establecimiento elaborador era incapaz de producir 7 mil toneladas mensuales (aproximadamente 152.000 quintales españoles). En ese año 1878 -lo mismo en los seis siguientes- lograría un promedio mensual de 4.780 toneladas $^{56}$. Por lo demás, a esas alturas el pastel era incomible para todos; el Presidente Prado había adjudicado el negocio al Banco La Providencia y este lo había transferido de inmediato a la sociedad creada para tal efecto, la Compañía Nacional de Salitre, más tarde Compañía Salitrera del Perú. La consignación fue entregada a James Sawers \& Co. y, tras su quiebra, a Graham Rowe \& Co, que llegó a una acuerdo con "la Casa"

Un par de ideas complementarias antes de terminar. Según manifestó a Londres un miembro de GGC

"Los Directores (de la CSFA) están plenamente conscientes del hecho que su negativa a colaborar en llevar adelante el monopolio peruano puede atraerles la hostilidad del Gobierno, y nosotros pensamos que, hasta cierto punto, ellos atribuyen a intrigas del Gobierno del Perú el último atentado del Gobierno boliviano de imponer un gravamen de exportación de 10 centavos por quintal. Pero aparentemente sienten que esos, o similares atentados, no se llevarán a efecto en la medida en que puedan contar con el cordial apoyo del Gobierno chileno, con cuyo respaldo están muy seguros de contar a través del partido de Edwards (el Nacional o montt-varista). Por tanto, al no temer esa posible hostilidad no están llanos a variar sus tácticas" ${ }^{58}$.

Mientras el derecho fuera de $10 \notin$ no evitaría la competencia al salitre de Tarapacá; en 1878 la CSFA elaboraba el quintal a un costo promedio de $\$ 1,35$ chilenos $^{59}$ versus casi $\$ 1,75$ promedio en las estatizadas oficinas peruanas, cuyas exportaciones estaban exentas ${ }^{60}$. Pero por ser un tributo mínimo podía elevársele a niveles insostenibles, tal como hasta eliminarla gravó Perú la exportación hecha por particulares (1,60 soles por quintal). Es evidente el beneficio que para el joint venture Peruvian Guano Co.-Anthony Gibbs \& Sons reportaría el que Bolivia incrementara a la CSFA el costo de su salitre puesto a bordo. De ahí las dudas sobre la sinceridad de las expresiones epistolares de "la Casa" acerca del "abominable atentado del gobierno de Bolivia en contra de los privilegios de la empresa chilena"61.

54 GMS 11.128 de 24.6.1878.

55 GMS 11.471/6 de 15.7.78.

56 Memorias anuales de la Compañía consultadas en la Biblioteca Nacional de Santiago.

57 Amayo Enrique, "Crisis y clase dominante: Perú 1876-79", en Reategui Wilson et al., La guerra del pacífico, Lima, Universidad Nacional Mayor de San Marcos, Vol. I, 1979, 92.

58 GMS 11.470/2 de 28.5.1878.

59 GMS $11.470 / 3$ de 15.3 .1879 .

60 Yépez, op. cit., 79

61 GMS $11.471 / 6$ de 16.5 .1878 . 
